Geopolítica(s) Revista de estudios sobre espacio y poder ISSN: 2172-3958

\title{
La frontera norte como proceso
}

Manuel Ceballos Ramírez (comp.) (2009) Fenómenos sociales y urbanos transfronterizos entre México y Estados Unidos. Tijuana: El Colegio de la Frontera Norte, 175 pp. ISBN: 978-607-479-021-4.

Antes de comenzar podría ser interesante establecer una serie de criterios teóricos que nos permitan entender mejor la cuestión que se aborda en el libro de forma satisfactoria. De la misma forma que Fausto Ortega nos plantea la frontera MéxicoEE UU como un proceso cambiante y complejo que se construye en el espacio a través de movimientos y políticas de muy distinta índole ${ }^{1}$, los diversos aspectos de la zona fronteriza que se nos presentan en la introducción nos desvelan un proceso político que influye de forma sustancial en la diversas instituciones, políticas e intervenciones públicas y privadas que se dan en esta zona.

La intención del libro, tal y como se describe en su introducción, es ofrecer una narrativa de los diversos procesos transfronterizos que influyen en la formación de la frontera como una zona "dinámica y en constante cambio" (p. 24) y en relación que mantienen diversos actores con la frontera, a fin de bridar herramientas que permitan la generación de políticas públicas.

La organización que nos ofrece el libro en su estructura nos deja las reflexiones de una serie de expertos y expertas ligados al Colegio de la Frontera Norte, desde donde desarrollan esa tarea de establecer herramientas para la generación de intervenciones públicas en el área de la frontera. A lo largo de la obra se presenta una relectura de temas como: la historia transfronteriza, los aspectos laborales relacionados con la frontera, el desarrollo urbano de las ciudades fronterizas y su gestión, y las estrategias desarrolladas por las familias, especialmente las mujeres, en la apropiación del espacio transfronterizo (pp. 21-23).

Cuando en 1873 Turner escribe El significado de la frontera, esta adquiere ya en el desarrollo del discurso una serie de características que la convierten en un elemento esencial a la hora de comprender la historia política de los EE UU. La frontera (frontier) se construye en torno a la significación cultural que el espacio va incorporando en la expansión hacia el oeste. Esta aproximación resulta interesante

1 Newman y Paasi nos relatan el proceso de fronterización como algo más que un producto esencializado, fijo e inmutable. Se nos plantea como un proceso complejo que desborda las concepciones clásicas de soberanía para establecerse como un producto político que no sólo “contiene” la soberanía sino que supone un espacio de encuentro y mezcla que termina produciendo relaciones sociales en torno a él y que dificultan su caracterización en términos clásicos (D. Newman \& A. Paasi, A.: "Fences and neighbours in the postmodern world: boundary narratives in political geography”, Progress in human geography, vol. 22, núm. 2, 1998, 186-207). 
a la hora de establecer los parámetros históricos en los que se basa la relación de los EE.UU. y México con sus respectivas fronteras. Siendo la de los EE UU una mitificación que lleva a expresar a los pioneros como una heroica batalla contra la naturaleza en busca de tierras fértiles ${ }^{2}$, la narrativa que se manejará en México y la exposición que se nos realiza en el libro difiere de esta.

Ceballos Ramírez comienza esclareciendo y posicionando geográficamente este área fronteriza en "la vertiente norte, que abarca del Golfo de México al Océano Pacífico" (p. 32) para atravesar así la historia de "la frontera norte” a través de los hitos que la han constituido y las diversas visiones que la construyeron. Ceballos cita a David Weber para extraer una conclusión que conecta con una visión de "la frontera entre Estados Unidos y México [más que] como una línea que separa pueblos, [...] [como] una zona permeable donde las culturas interactúan en zigzagueantes combinaciones y permitas” (p. 33). Esta conceptualización permite por tanto abordar las cuestiones relativas a los diversos encuentros que fundan en cierta medida los aspectos más reconocibles de la frontera para así entrever las diversas interrelaciones que se dan entre ambas sociedades.

Los diversos hitos que Ceballos Ramírez elige para desentrañar la historia de la frontera se corresponden con una serie de realidades presentes en este espacio a nivel geográfico, económico y político-narrativo. Como veremos esto nos deja diversas problematizaciones sobre las que centrar la atención, comenzando por un repaso a la historia política y la cuestión texana -léase, el conflicto que, de alguna forma, hace aparecer la frontera norte como una realidad político-social (p. 33)-.

Lo paralelo de los procesos que se describen a lo largo de toda la obra se encuentra en este punto de un modo algo más sintético, que permite destacar los aspectos más llamativos. Tanto la cuestión texana —es decir, la independencia de Texas- y la posterior inclusión del estado en los EE UU y a lo que Ceballos Ramírez denomina "la leyenda negra" sirven, a pesar de resistir mal a la presión historiográfica, como ideas fundantes de las varias concepciones que se vendrán sosteniendo en torno a la frontera. Estas dos cuestiones abarcan el abordaje histórico de cómo se ha percibido la frontera. Concretamente y en relación a la "leyenda negra" —a la que nos referimos como la separación de corte civilizatorio- la frontera se constituye como el punto de fractura entre el norte y el sur, lo desarrollado y lo bárbaro. En ese sentido, tanto desde los EE UU como desde México se quiso hacer percibir la frontera como un "un campo abonado para [...] actividades ilícitas" (p. 36).

El autor reflexiona sobre los procesos paralelos que se han ido dando a lo largo de la historia de la frontera, a los cuales hay que añadir ese carácter convergente que caracteriza las sociedades fronterizas. Tanto en la economía y el comercio como en el desarrollo urbano (pp. 37-38) se pueden destacar elementos de unión entre ambas sociedades que han ido fraguando a pesar de las “disposiciones legales" de cada uno de los Estados. Si bien es cierto que la historiografía estadounidense ha tratado la cuestión desde la perspectiva de la "leyenda negra" en la que los EE UU aparecen como la locomotora de desarrollo, los procesos son muchos y complejos, y la colaboración y el conflicto han ido apareciendo a lo largo del tiempo. Los espacios que se abren a la colaboración económica y la realidad de las "ciudades

2 F. J. Turner: “El significado de la frontera en la historia americana”, Secuencia, 7, 1987, 187-195. 
gemelas" se han ido consolidando, permitiendo que aparezcan instituciones en torno a la gestión de ambas realidades como el TCLAN y otras organizaciones de gestión urbana en la frontera.

Este brevísimo repaso concluye con la mención especial que ocupan tanto las actividades políticas y sociales como el trabajo migratorio en el espacio transfronterizo. Ambas se establecen como realidades presentes tras el Tratado de Guadalupe Hidalgo tras la guerra. Los intercambios culturales y lingüísticos, y la presencia de trabajadores mexicanos tras la frontera desde los inicios de esta, han permitido hablar de un proceso "a tal grado que en su ir y venir llegaron a borrar las líneas que dividen a un país del otro, creando un espacio binacional” (p. 38). Es por esto que este espacio "zigzagueante" y complejo se ha ido formando en torno a la estrecha unión que se produce tanto por la cercanía geográfica como por los procesos políticos puestos en marcha a ambos lados, a pesar de las enormes dificultades que se hallaron en su desarrollo ${ }^{3}$.

Otro de los aspectos que redundan en la condición "binacional” y "zigzagueante” del área fronteriza son las relaciones laborales entorno a la frontera. Siguiendo la tesis que empapa toda la obra, es de suponer que estos procesos, a los que le sobreviene la complejidad añadida de su carácter fronterizo, no dependen únicamente de la evolución en las relaciones de producción sino también de la forma en que los actores viven y producen a diario el territorio mismo. En el siguiente capítulo, Quintero Ramírez introduce la cuestión laboral en la zona transfronteriza, además de acompañarnos en un recorrido histórico del desarrollo del movimiento obrero a ambos lados de la frontera. En este capítulo se da una exposición "de manual" de lo que podemos llamar el desarrollo de las fuerzas productivas y del aumento de la conflictividad laboral que acarrean. Lo específico del aspecto fronterizo del territorio nos deja una imagen contradictoria entre el nacimiento y las victorias del movimiento obrero en los EE UU y las terribles vicisitudes que los trabajadores mexicanos tuvieron que atravesar tanto a un lado como al otro de la frontera.

La periodización histórica basada en los diversos modelos productivos que se ponen en marcha en la zona fronteriza, con los flujos y reflujos de trabajadores que pasarán de un lado a otro de la frontera, constituye la principal línea argumental del capítulo. La frontera aparece como un elemento esencial para el análisis dada la enorme dependencia que existe entre las áreas que la forman (p. 50) y la influencia que posee en la formación de las estrategias sindicales de los trabajadores. El desarrollo posterior es historia. Con el fin de la Segunda Guerra Mundial ambos gobiernos jugarán un rol activo en la regulación de la actividad sindical protegiéndola, por un lado, pero sin dejar de integrarla para evitar conatos radicales. Es posiblemente a partir de los 70 donde la creación de instituciones reguladoras de la actividad económica en la franja fronteriza inició un proceso que culminaría de forma clara en 1994 con la instauración del Tratado de Libre Comercio de América del Norte (TCLAN/NAFTA), acompañado además por la puesta en marcha de políticas neoliberales de privatización y desregulación (p. 71). Lo realmente llama-

Tanto es así que una de las figuras más asociadas desde la cultura pop a la “esencia” estadounidense como es la del cowboy o vaquero, está enormemente influenciada por la presencia mexicana al otro lado de la frontera (J. Haeber: "Vaqueros: The first cowboys of the open range", National Geographic News, 15 de Agosto de 2003). 
tivo de esta investigación es el hecho de que las dificultades añadidas al racismo y la desconfianza que pueblan la "leyenda negra", mantienen una relación estrecha con el área en la que se desarrollan. El reto para los sindicatos fundados por los trabajadores mexicanos adquiere una doble dimensión a la que han de enfrentarse de manera simultánea: por un lado, la adaptación constante a los cambios intrínsecos de una economía "dependiente"; por otro, el riesgo para su independencia y capacidad de acción que conlleva el que el resto de instituciones imaginen este espacio estratégico en términos de dependencia. En un contexto tal, la posibilidad de acción política se ve coaccionada. Y, sin embargo, vemos que los desafíos a los que se enfrentan las clases trabajadoras a ambos lados de la frontera tienen más similitudes que las que los propios agentes sindicales que actúan en el territorio reconocen. El modelo de las industrias maquiladoras en crisis se correlaciona con el bienestar económico al otro lado de la frontera y viceversa. Es por ello que cualquier solución que no aporte una visión de la frontera en los términos "binacionales” antes mencionados, difícilmente podrá atajar el problema.

¿De qué forma podríamos decir por lo tanto que se proyectan en el territorio las diversas concepciones que se manejan de la frontera? En esta obra se dos realidades que podrían expresarse de esta forma: la primera, el urbanismo, la segunda, las formas de apropiación del territorio que realizan los individuos.

Desde el compromiso metodológico multidisciplinar (p. 88) la reflexión que sigue sobre la realidad urbana de la región fronteriza afronta el reto de complejizar un proceso que tiende a analizarse como homogéneo dadas las connotaciones que lo "regional" ha tenido en la literatura (p. 85). [Al] comprender las ciudades como núcleos esenciales en los nuevos procesos de regionalización vinculados con los imaginarios disponibles en la era de la globalización ${ }^{4}$, se nos presentan procesos relacionados con la Industria Maquiladora y los efectos que estos tienen a la hora de desarrollar el llamado "corredor NAFTA" (p. 99). De esta forma se contraponen los conceptos de "metrópoli fronteriza" al de "urbanización bilateral adyacente" (UBA) (p. 92). La distinción entre ambas fórmulas es oportuna en tanto que la regionalización como proceso basado en las divergentes fórmulas de urbanización que se aplican considerando las diversas interacciones entre actores en el terreno, ofrecen formas distintas de consolidar las relaciones y de como estas se reflejan en la práctica sobre el territorio en contraposición a la metrópoli; concepto, por su parte, desarrollado en pro de establecer una herramienta que unifique la comprensión de la movilidad laboral y los servicios ofertados en el área. Además de una gestión más o menos unificada, en este caso, los diversos centros urbanos se plantean como estructuras diferenciadas, en términos de Alegría "juntos pero no revueltos" ${ }^{5}$. Resulta interesante contraponer ambas concepciones de centros urbanos en la frontera dada las características específicas que se dan en el área, las UBA se han ido desarrollando en condiciones extremas (p. 96), y aunque son enormemente dependientes de los procesos que se dan a nivel nacional (económicos, especialmente) retienen una mayor capacidad de recuperación ante las crisis (p. 97).

$4 \quad$ N. Brenner: "La formación de la ciudad global y el re-escalamiento del espacio del Estado en la Europa Occidental post-fordista”, EURE (Santiago), vol. 29, núm. 86, 2003, 5-35.

5 T. Alegría: “Juntos pero no revueltos: Ciudades en la frontera México-Estados Unidos”, Revista Mexicana de Sociología, vol. 62, núm. 2, 2000, 89-107. 
El tono general del estudio radica en la importancia que tiene la perspectiva de la "regionalización dinámica y heterogénea" (p. 124). Este enfoque aboga por una comprensión de las geografías económicas desde parámetros que permitan una diferenciación rompedora con la homogeneización presupuesta a la condición regional. La principal característica destacada por lo autores sería el crecimiento urbano impulsado por la presencia de la industria maquiladora ${ }^{6}$. Esto posiciona a las UBA en un margen de crecimiento de la población algo superior al resto de los centros urbanos de características parecidas. Además, ofrece una herramienta que permite a las instituciones a ambos lados de la frontera México-EE UU apostar por una coordinación sustancial - recogida, por su parte, en diversos tratados internacionales - para calibrar y componer políticas públicas.

Es importante ligar las propuestas de urbanización con la comprensión territorial de la disciplina que nos propone Schneider ${ }^{7}$. Es en esta lectura cuando apreciamos la necesidad de fijar las poblaciones en áreas concretas y cuando la lógica de la gubernamentalidad estatal aparece con la frontera y su expresión en el espacio. Es por ello que el "momento territorial de la disciplina" obra un especial sentido cuando hablamos no sólo de la regionalización en sí misma, sino de la atención que debemos prestar a la realidad fronteriza, es decir, a la cotidianeidad porosa entre el norte y el sur que se explicita en el área transfronteriza México-EE UU.

¿De qué formas pueden los individuos y los grupos relacionarse con el espacio que pueblan? Para intentar responder esta pregunta acerca de la convivencia que las personas mantienen con la frontera más traspasada del mundo, Cueva y Vásquez nos proponen una visión que pretende categorizar la forma en la que las familias transfronterizas se forjan (p. 157). La noción de familias transfronterizas responde a la necesidad de explicar un proceso que se produce de forma repetida desde el tratado Guadalupe-Hidalgo, con varios picos de ida y retorno como el acaecido con la crisis de los 30, dónde la repatriación, acompañada por políticas de reparto de la tierra, fue promovida por la administración Cárdenas (pp. 157-158). El objeto de la investigación, centrada en este caso en las estrategias desplegadas por las mujeres al lado mexicano a la hora de dar a luz, se entiende como una forma radical de apropiación (p. 183). Lo llamativo de este estudio es que la concepción de la frontera como espacio potencialmente apropiable implica que estas estrategias que se formulen en torno a las características propias del lugar como "binacional". En este sentido, las autoras enfatizan el hecho de que la decisión sobre dónde dar a luz, a pesar de estar mediada por las condiciones económicas en las que se encuentran las familias y todo lo que se deriva de estas, deben ser leídas como un intento de apropiarse y reproducir la especificidad transfronteriza (p. 183).

Evidentemente, esto engarza a la perfección con la tesis que se viene defendiendo desde el principio: la frontera como un espacio de encuentro en el que las diversas instituciones que la pueblan despliegan ciertas estrategias concordantes a esta concepción de la misma, a la vez que un espacio que aquellas otras instituciones

6 El formato no me permite hace mucho hincapié sobre el tema en sentido gráfico, es por ello que es recomendable consultar los cuadros y gráficas de los que dispone el capítulo en cuestión, todo ellos muestran el crecimiento y las diversas posiciones que han ido ocupando las UBA en los ránquines de población (pp. 100, 102110, 119-122).

7 S. Schindler: “Governing the twenty-first century metropolis and transforming territory”, Territory, Politics, Governance, vol. 3, núm. 1, 2015, 7-26. 
que actúan sobre ella desde otros espacios o que la "desterritorializan” suelen imaginar en términos esencialistas.

Es por ello que estos estudios de realidades concretas nos permiten establecer, a pesar de las diferencias en servicios o niveles de desarrollo tal y como se plantean en el norte, una serie de parámetros a través de los que comprender los espacios fronterizos. Es interesante en ese sentido entender que otra de las razones que aúpan a las mujeres a decidir dónde dar a luz es el tipo de servicio médico que se presta en a cada lado de la frontera. Es por ello necesario un estudio comprometido con la comprensión del proceso en toda su complejidad y que permita huir de esencialismos..

Jesús M. Fernández Cano

Facultad de Ciencias Políticas y Sociología

Universidad Complutense de Madrid

Email: jesufe04@ucm.es 